\title{
Substantiation of the selector drum parameters of the universal seeding device of the innovative seeder
}

\author{
Erkin Farmonov $^{1 *}, B$ Khudayarov $^{1}, T$ Abdillaev $^{1}$, and $F$ Farmonova $^{2}$ \\ ${ }^{1}$ Tashkent Institute of Irrigation and Agricultural Mechanization Engineers, Tashkent, Uzbekistan \\ ${ }^{2}$ Tashkent State Agrarian University, Tashkent, Uzbekistan
}

\begin{abstract}
A review of technologies for sowing non-loose seeds of forage plants shows that seeders and devices that fully meet the requirements of agricultural technology have not yet been created. The available tools do not provide a stable sowing of seeds and their uniform placement in the field, so the distances between the nests are not the same in a row. The authors recommend designing the sampling drum for an innovative universal seeding machine with measuring grooves that ensure the same distance between the seed nests in a row, corresponding to the agrotechnical requirements for seeds. The main requirement when creating a seeder was the need to determine the number of grooves that determine the distance between the nests at different speeds of the unit. In addition, it is also required to ensure that the measuring grooves are filled with the required amount of seeds, which depends on the speed of rotation of the sampling drum. Based on preliminary laboratory experiments and theoretical studies, the optimal parameters of the sampling drum were determined: the diameter of the sampling drum is $100 \mathrm{~mm}$; the speed of rotation of the sampling drum is $8-15 \mathrm{rpm}$; the number of measuring grooves $-10-12$ pieces. These parameters at a speed of MTA $-1.44 \mathrm{~m} / \mathrm{s}$ provide the distance between the seed nests in a row and are 0.5-0.7 m.
\end{abstract}

\section{Introduction}

The devices recommended for sowing non-flowing seeds of fodder plants [1-8] do not provide sowing of seeds of a given rate, as well as the distance between nests in a row. With the general instability of work, these devices and uneven sowing of seeds do not ensure the fulfillment of agrotechnical requirements. While improving the sowing technology, the former authors, and seeding devices, the main attention was paid to the decision of the selection of seeds from bunkers [9-12]. However, these works do not contain data on the seeding rate of the seeding device when the uniform distance of the seed nests in the row is provided.

\footnotetext{
* Corresponding author: Erkinfarmonov2009@mail.ru
} 


\subsection{Analysis of the current state of the problem under consideration}

As a result of a critical scientific analysis of the shortcomings of the devices mentioned above, a sampling drum with measuring grooves was created for the universal seeding device of an innovative seed drill, which provides ordinary row sowing of seeds of the desert forage plants, including saxaul and cherkez, while ensuring the established norms and consumption of seeds and between nests (figure 1) [13-17].
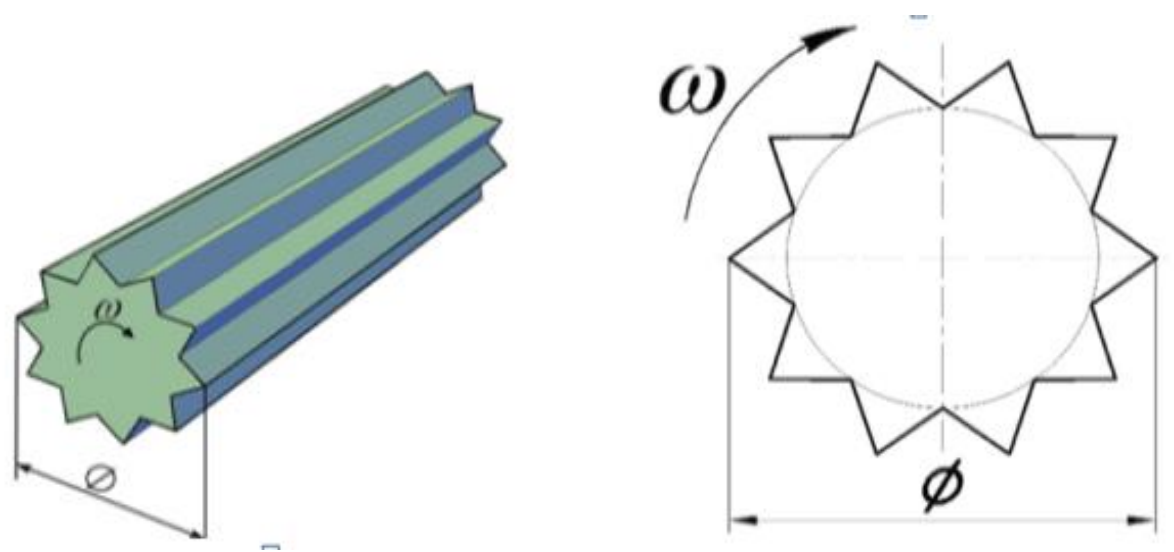

Fig. 1. Diagram of the outgoing drum with measuring grooves

Agrotechnical requirements, the distance between nests on the crops, saxaul, and cherkez, is $0.50-0.70 \mathrm{~m}$ [18-20.]. To ensure these requirements, we investigated the speed of the MTA movement, the rotation speed of the sampling drum and select the number of measuring grooves on it.

When sowing seeds of saxaul and cherkez, the MTA moves at a speed of $\vartheta_{\mathrm{a}}=1.44 \mathrm{~m} / \mathrm{s}$ $(5,18 \mathrm{~km} / \mathrm{h})$. The uneven micro-relief of the sandy desert soil, the presence of semi-shrubs, and other obstacles do not allow the MTA to move at a higher speed.

\section{Methods}

Whensubstantiating the parameters of the seeding device, in the beginning, the speed of the MTA was taken, taking into account the peculiarities of the microrelief and the presence of obstacles in the field, as well as the speed of rotation of the selection drum, when the distance between the seed nests $(0.60-0.70 \mathrm{~m})$ is provided when sowing in a row. The experiments were carried out at a sampling drum rotation speed of $8,10,15,20,30,40,60$ rpm, changing the number of measuring grooves by 1-18 pieces.

It was found that with an increase in the rotation speed of the sampling drum, the filling of the measuring grooves with seeds from the hopper sharply decreased, and a gap appeared between the seed arches at the top and the measuring grooves, which made the measuring grooves take seeds much less than the established norm.

\section{Results and Discussion}

The angular speed of the sampling drum is determined using the following formula [21].

$$
\omega=\frac{2 \pi \vartheta_{a}}{l_{n} \cdot i_{g}}
$$


here, $\pi=3,14 ; \vartheta_{\mathrm{a}}=1,44 \mathrm{~m} / \mathrm{s}$ is the speed of movement of the MTA; $l_{\mathrm{n}}$ is the distance between the seed nests sown in a row, $l_{\mathrm{n}}=0,5-0,7 \mathrm{~m}$.; $i_{\mathrm{g}}$ is the number of grooves, $i_{\mathrm{g}}=1$, $2,3,4,5$ pieces.

Here, by changing the values of $l_{\mathrm{n}}$ and $i_{\mathrm{g}}$ relative to each other, we determine the necessary angular speed of the sampling drum.

Graphs are plotted based on the obtained values (Figures 2, 3, and 4).

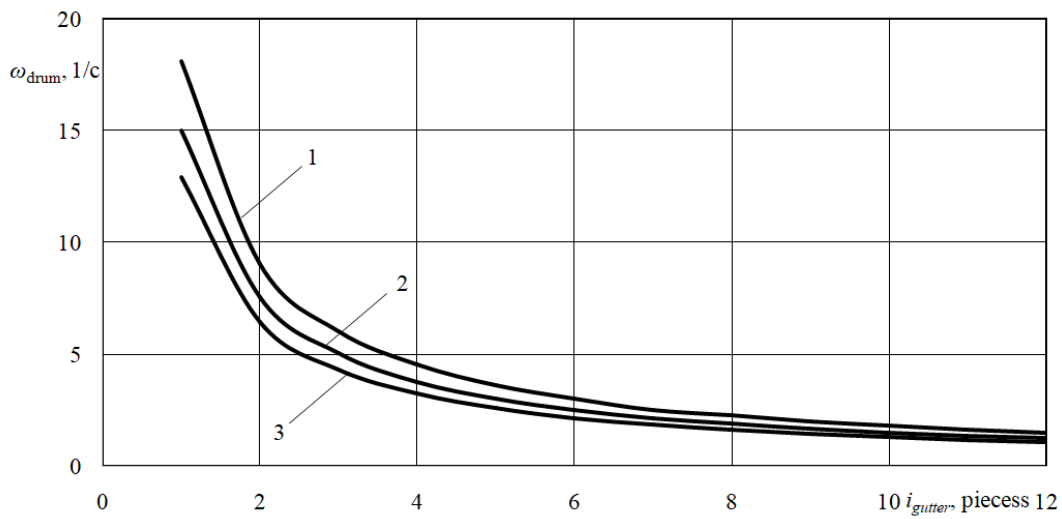

Distance of sown seed nests in a row: 1 is $l_{\mathrm{n}}=0,5 \mathrm{~m} ; 2$ is $l_{\mathrm{n}}=0,6 \mathrm{~m} ; 3$ is $l_{\mathrm{n}}=0,7 \mathrm{~m}$.

Fig. 2 Graph of the change in the angular speed of the sampling drum depending on the number of measuring grooves

The graph shows that as the number of measuring grooves increases, the required angular speed of the sampling drum decreases. The regularity of the change in the angular speed of the sampling drum depending on the number of measuring grooves varies according to the laws of the concave parabola. According to the graph, the optimal number of measuring grooves $i_{\mathrm{g}}=10-12$ pieces is taken when the angular speed of the sampling drum $\omega_{\mathrm{d}}=1.50-1.80 \mathrm{~s}^{-}{ }^{1}$ will be sufficient to fill the grooves. The accepted values provide the required distance of seed nests in a row, $l_{\mathrm{n}}=0.5-0.7 \mathrm{~m}$.

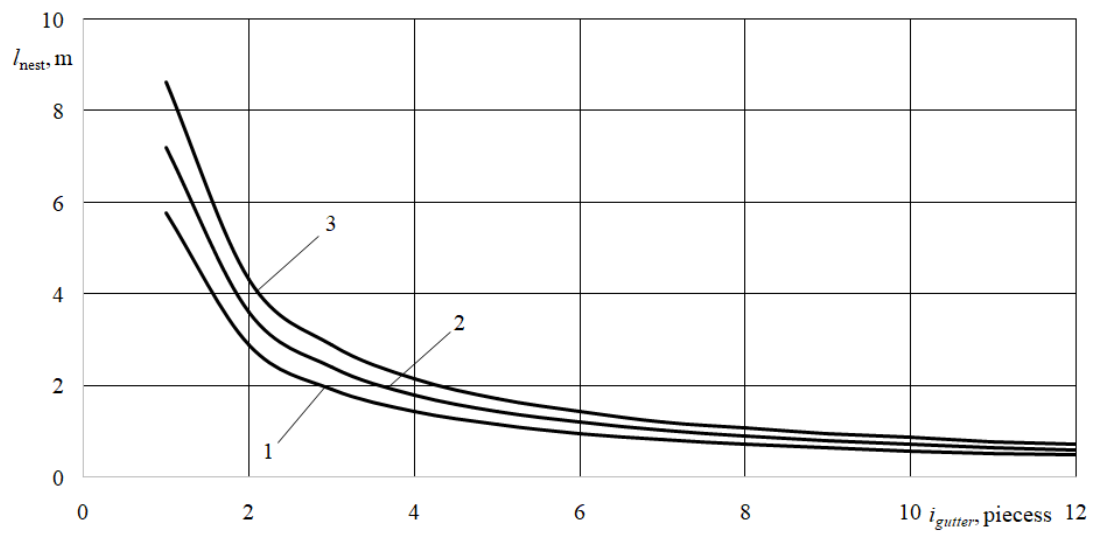

The number of revolutions of the sampling drum, rpm: 1 is $i_{\mathrm{g}}=15 ; 2$ is $i_{\mathrm{g}}=10 ; 3$ is $i_{\mathrm{g}}=8$.

Fig. 3 Graph of changes in the distance between the sown nests in a row depending on the number of measuring grooves of the selection drum. 
The graph shows that the distance between the seed nests in a row decreases with an increase in the number of measuring grooves. The number of measuring grooves and the distances between seed nests in a row are correlated by the concave parabola law. In this case, the optimal number of measuring grooves is $i_{\mathrm{g}}=10-12$ pieces, and the distance between the seed nests in the row is $l_{\mathrm{n}}=0.5-0.7 \mathrm{~m}$.

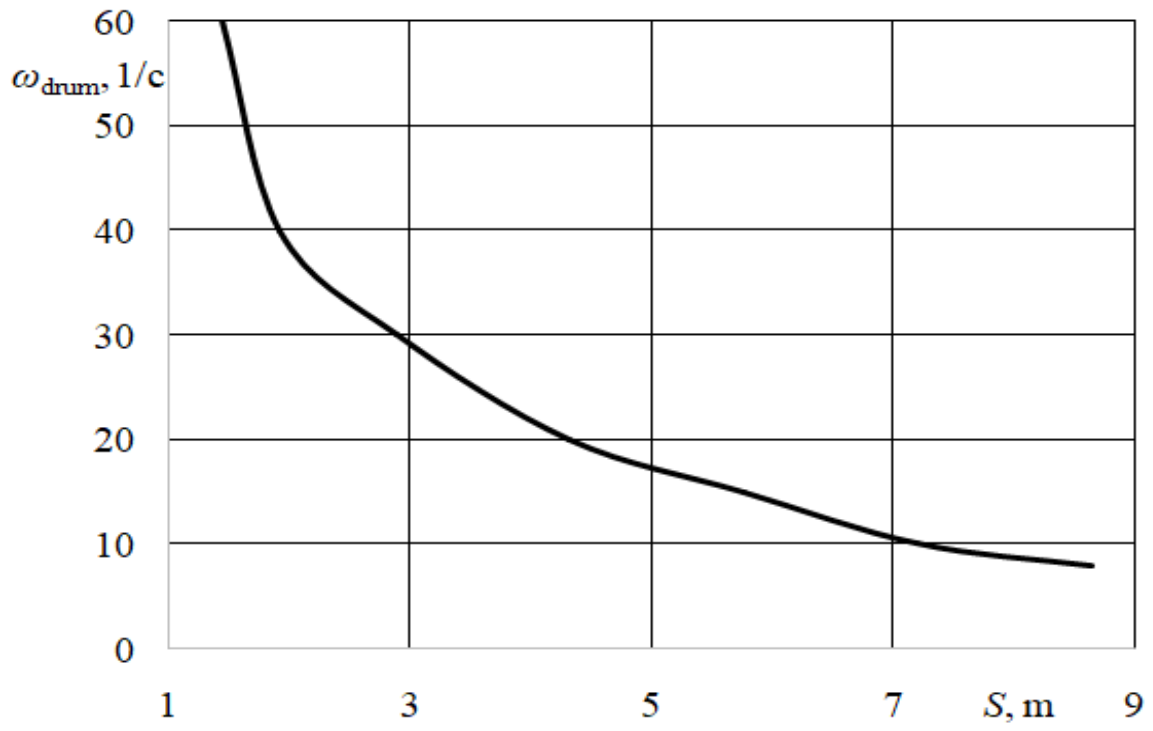

Fig. 4 Graph of the change in the distance passed by the MTA depending on the number of rotations of the sampling drum

You can see from the graph that the number of drum rotations decreases as the distance passed by the MTA increases. The distance passed by the MTA and the number of rotations of the sampling drum correlate according to the law of concave parabola lines. Here, the optimal distance passed by the MTA is $S=8.64-5.76 \mathrm{~m}$ and the number of rotations of the sampling drum $n_{\mathrm{b}}=8-15 \mathrm{rpm}$.

\section{Conclusions}

1. Currently, there is no sowing unit that could sow non-loose seeds of desert plants at a given rate evenly and stably with the same distance between the sown nests in a row. A new sampling drum with measuring troughs is created, which ensures the sowing of nonloose seeds of desert forage plants, including saxaul and cherkez, at a given rate, observing the same distance between the seed nests in a row;

2. At the specified speed of the MTA movement $(1,44 \mathrm{~m} / \mathrm{sec})$ to ensure the same distance between the seed nests in a row, the recommended speed of rotation of the sampling drum is $8-15 \mathrm{rpm}$; the number of measuring grooves on it is $10-12$ pieces; the diameter of the sampling drum is $100 \mathrm{~mm}$.;

3. When sowing saxaul and cherkez seeds with an innovative seed drill with a universal seeding device, manual labor is significantly reduced. Seeds are sown efficiently, evenly, and stably throughout the field. As a result, pasture productivity increases dramatically. This is one of the key factors in the development of pasture seed production. 


\section{References}

1. Musaev T. Research and substantiation of the parameters of the seeding apparatus for sowing seeds of desert fodder plants in astrakhan pastures in Uzbekistan] Abstract dis. cand. tech. sciences. Tashkent, 1969, p34.

2. Toshboltaev M.N., Sadirov A.N. To'laganov B. Q., G`ofurova L.A., Nabiyeva G.M., Rabbimov A. Recommendations for growing seeds of desert edible plants]. Tashkent, 2016, 22p.

3. Kurzov P.K., Plashvskiy M.A., Vinniskiy S.Y., Krivoshey M.H., Ponomarenko N.G., Andrenko G.P. Seeder for seeding low-flowing and non-flowing materials Discoveries Inventions. -1971.№ 9.

4. Arslanov M.A. Design parameters of the seeding part of the seeder for sowing non-loose grass seeds in a wide-row method. //Abstract of the dissertation of the candidate of thetechnical sciences. Nalchik: 2007.p 23.

5. Astanakulov K.D., Obidov R., Khaziev S.A., Umurzakov Z.A. Restoration of degraded karakul pastures in Uzbekistan // Technical support of agriculture., No. 1 (1), 2019, Pp.145-152

6. Shaymardonov B.P., Ibragimov D.A., Aripov A.O., Mirsaidov R., Mamadjanov S.I. Agricultural machines for improving the arid pastures. Tashkent: Economics Publishing House, 2018. Pp 33-58.

7. Islomov E. I. Substantiation of the parameters of the combined tool for improvement the arid pastures of Uzbekistan. Abstract of the dissertation of the candidate of technical sciences. - Tashkent: 2019. p34.

8. Kryuchin N. P. Mechanization of seeding of the phytomeliorant plants. Inovatika andexpertise, 2017. Issue 2 (20) pp. 205-209.

9. Eviev B.A., Belyeva B.I., Ochirov N.G. Technologies and technical means for sowing non-flowing seeds offorage grasses. // In the collection: Fundamentals of scientific, technical andtechnological modernization of theagro-industrial complex (FONT and TM-APK-13) materials of the All-Russian scientific and practical conference. - 2013.Pp 343-347.

10. Turkxachev E.D., Maliev V.Kh. Substantiation of the operating mode and design parameters of the seeding part of the seeder for sowing non-loose seeds of forage plants.//Bulletin ofthe Agro-industrial complex of Stavrapolye-2013-№2 (10)Pp127-131

11. Aduov M.D., Nukusheva S.A., Kaspakov E.JSubstantiation of the design parameters of machines for sowing non-dry grass seeds.// International scientific journal of mechanization inagriculture and economy of resources, web ISSN 26033712; printing issn 2603-3704. YEARLXV, ISSUE 2, Pp. 50-52 (2019).

12. Posharikov F. V., Popov V. Results of research of a new seeding apparatus of a forest seeder.Modern problems of science and education. 2012. No. 1. p. 159

13. Farmonov E.T., Korsun A.I., Gorlova I.G. Patent RUz № 04515. Wide-grip seeder Byull.-2009.- No.7.

14. Farmonov E.T., Aliqulov S., Farmonova F.E. Improving the sowing of seeds of desert crops. Proceedings of the international scientific-practical conference on the forageproblems of increasing the efficiency of electricity in the agro-industrial sector, Tashkent,2018, November 28, Part III, Pp.39-43.

15. E. Farmonov, A. Igamberdiev, A. Sadirov, F. Farmonova, Sh. Aynakulov. Model fordetermining the parameters of the distribution drum of the sowing seeder hopper of seeds of the desert fodder plants. International Journal of Recent Technology and Engineering (IJRTE) ISSN: 2277-3878, Volume-8 Issue-4, November 2019 Pp 7648-7650 
16. Farmonov Erkin, Sadirov Amir, Berdimuratov Parakhat, Tulaganov Bahtiyor, Mirnigmatov Botir. Improvement of sowing units to strengthen the feeding of aridic livestockbreeding. International Journal of Recent Technology and Engineering (IJRTE) ISSN:2277-3878,Volume-8 Issue-4, November $2019 \mathrm{Pp}$ 7651-7654

17. Farmonov E., Abdilaev T., Ismoilova Z., Farmonova F. To the issue of mechanized sowingof seeds ofthe desert fodder plants. //for taking part in the International Scientific Conference «Costuction Mashines, Hudraulics and Water Resources Engineering» (CONMECHYDRO-2020) held on April 23-25, 2020 in Tashkent, Uzbekistan Pp1-6.

18. Agrotechnical requirements for a seed drill for sowing seeds of saxaul, cherkez and forage grasses in deserts and semi-deserts. A collection of the ATT at the AGM and tractors. Moscow, 1969, Volume XI, section XII, p. 343...346.

19. Specialists of scientific institutions. On the creation of shrub-semi-shrub pastureprotected plantations in the desert and semi-desert regions of Uzbekistan. Instructiveinstructions. Tashkent, 1982. p.5.

20. Shamsutdinov Z. Sh., Ibragimov I. O. Long-term pasture agrophytocenoses in the arid zone of Uzbekistan. Tashkent, 1983, Pp.79-81.

21. Boboev U. P. Substantiation of the parameters of the support-leveling roller of the frontal plough // Author's abstract of the dissertation of the candidate of the technical sciences. - Tashkent: 2007. p.16. 